\title{
STRUCTURE AND SHEAR RESPONSE OF LIPID MONOLAYERS
}

\author{
Progress Report
}

for the period July 1, 1989 - June 31, 1990

Pulak Dutta and John B. Ketterson

Northwestern University

Evanston, IL 60208

February 1990

prepared for

THE U.S. DEPARTMENT OF ENERGY

Agreement no. DE-FG02-84ER45125

\section{NOTICE}

This report was prepared as an account of work sponsored by the United States Government. Neither the United States nor the Department of Energy, nor any of its employees, nor any of their contractors, subcontractors, or their employees, makes any warranty, express or implied, or assumes any legal liability or reponsibility for the accuracy, completeness or usefulness of any infoimation, apparatus, product or process disclosed or represents that its use would not infringe privately-owned righrs. 
Department of Energy Grant no.: DE-FG02-84ER45125

Principal Investigators: $\quad$ P. Dutta, J.B. Ketterson

Department of Physics \& Astronomy

Northwestern University

Evanston, IL 60208

\section{CONTENTS}

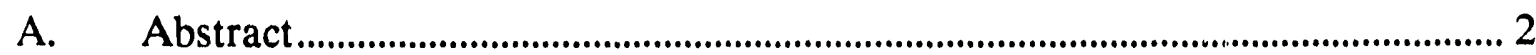

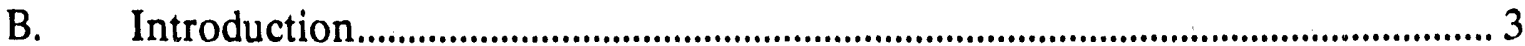

C. Diffraction studies of monolayer structure and phase diagrams ......................... 3

i. Instrument design and construction....................................................................

ii. Structure of the 'solid' phase in fatty acids and alcohols..................................... 8

iii. Effect of subphase ions on monolayer structure ............................................ 9

iv. Phase diagrams of acid and alcohol monolayers ............................................ 12

D. Flow of surfactant across a thin liquid film wetting a solid substrate .............. 16

E. Mechanical properties of surface monolayers.................................................. 19

F. Static and dynamic contact angles as a probe of LB deposition...................... 23

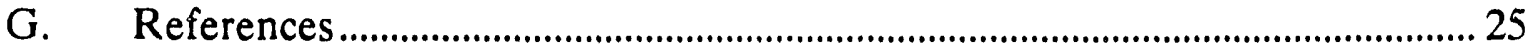

Appendices:

I List of papers supported by this grant .................................................... 27

II List of talks and posters describing grant-supported work.................... 29

III Reprints and preprints 


\begin{abstract}
Organic monolayers and multilayers are both scientifically fascinating and technologically promising; they are, however, both complex systems and relatively inaccessible to experimental probes. In this Progress Report, we describe our X-ray diffraction studies, which have given us substantial new information about the structures and phase transitions in monolayers on the surface of water; our use of these monolayers as a unique probe of the dynamics of wetting and spreading; and our studies of monolayer mechanical properties using a simple but effective technique available to anyone using the Wilhelmy method to measure surface tension.
\end{abstract}




\section{B. Introduction}

Few areas of science are as interesting and as 'relevant' as the study of organic thin films. Progress towards an understanding of these systems requires a multidisciplinary approach using a variety of experimental techniques, Moreover, because of the relative inaccessibility of these films to many of the standard tools available to those studying bulk systems or inorganic thin films, the development of new experimental probes and the successful application of existing techniques to these systems are of the utmost importance.

During the last three years, we have successfully used X-ray diffraction for detailed studies of the structure and phase transitions of monolayers on the surface of water; we have devised and used a simple technique sensitive to the shear properties of these monolayers; and we have used these monolayers in turn as a probe of wetting and spreading of thin liquid films. Our results in each of these areas are described in the following sections.

\section{Diffraction studies of monolayer structure and phase diagrams}

Ever since Irving Langmuir reported ${ }^{1}$ (in 1917) that the isotherms of organic monolayers on water showed discontinuities implying multiple phases, scientists have studied these systems using a great variety of experimental techniques ${ }^{2}$. However, in spite of the large volume of published work, no structural information had been available before 1987, when we ${ }^{3}$ and another group 4 published the first X-ray data. Even today, most studies simply assume structures (such as 'liquid condensed') that are selected by virtue of not being inconsistent with the data being reported. Given this context, the importance of diffraction and other direct structural techniques cannot be overemphasized. Since our first relatively primitive results ${ }^{3}$, published at the beginning of the period described by this report, we have come a long way: by collecting diffraction data as a function of temperature and $\mathrm{pH}$ as well as of pressure, we have discovered previously unknown expanded and tilted solid structures, mapped out phase diagrams, and observed the effect of subphase ions on 
the structure of acid monolayers. Although we have not yet achieved an overall understanding of monolayer phase diagrams (now thought to be quite dissimilar for different systems, based on the variety of isotherms observed), nor completely determined the effect of head groups, tail groups and subphases on the structure of Langmuir films, we have made substantial and exciting progress in these directions.

Our experiments were performed at the National Synchrotron Radiation laboratory (NSLS) and at the Cornell High-Energy Synchrotron Source (CHESS). The experimental layout has been described in detail in Ref. 5; briefly, we used a platinum coated float glass mirror to reflect the X-ray beam downwards onto the water surface at less than the critical angle for total external reflection; scans were then performed both in the plane of the monolayer and (in our most recent experiments) normal to it. X-ray wavelengths of about $1.5 \AA ̊$ were used in all our experiments. Soller slits were used to define the beam both horizontally and (in some cases) vertically. Construction of the sample chamber involved several unusual design considerations and so is described in greater detail in the following section.

\section{(i) Instrument design and construction}

Sample chambers for diffaction studies of Langmuir films are in principle simpler than those required for many other types of surface X-ray studies: a vacuum is not required, and only a moderate range of temperature must be covered. However, in practice there are several complications. The conductivities of both the subphase and the ambient atmosphere are poor, so that it is difficult to precisely determine or control the temperature at the air-water interface, or to prevent a high temperature gradient at this interface. (All work in this field by groups other than our own have reported room-temperature data only!) A vacuum cannot be maintained in the presence of water, and if the ambient gas is air there will be a large random scattering background. If the water evaporates, the resulting drift in the monolayer position can severely affect the alignment, given the glancing-incidence geometry. Finally, X-ray windows not maintained at or above the 
sample temperature will have condensation on the inside, while windows not maintained at or above room temperature will have condensation on the outside.

We have designed and built a Langmuir trough for $\mathrm{X}$-ray studies that addresses the problems listed above (Fig. 1a). The system was machined out of two aluminum plates, one for the trough and side walls and one for the lid. The resulting 'slimline' design minimizes subphase and airspace thickness, and thus increases temperature uniformity and decreases the response time when the temperature is changed. Channels machined below the trough and in the lid allow temperature control to $0.1^{\circ} \mathrm{C}$ using water from heating/refrigerating circulators. When closed, the enclosure is hermetically sealed; a helium atmosphere is maintained through quick-connects on the lid. The hermetic seal eliminates evaporation, and the use of helium not only reduces air scattering but (we discovered) prevents radiation damage of the monolayer, presumably by displacing oxygen. Two X-ray windows are machined into the side walls: a small entrance window, and a 'wrap-around' window allowing the exit of scattered X-rays from throughout the long 'footprint' of the glancing-angle X-ray beam. Mylar is used for the windows so that condensation may be observed visually (beryllium would not allow this); the mylar pieces are held down with 'picture frames' pressing down on o-rings. Heating tape under the windows is used to convectively heat the mylar and thus prevent condensation.

Fig $1 \mathrm{~b}$ shows an external view of the trough enclosure. The lid rides on two vertical posts allowing it to be lifted for access to the trough. A piece of filter paper hanging from a Cahn electrobalance is used to measure surface tension; the use of a bellows around the string allows the lid to be lifted without disturbing the measurement. The entire system is driven up and down by a stepper motor for alignment in the X-ray beam, and rests on a constant-position electronic vibration-isolation table (Newport EVIS); the latter is particularly effective at the low frequencies to which the water surface is most sensitive.

The above description concentrates on some specific features of the system; for a more complete description than is possible in this space, see Ref. 6. 


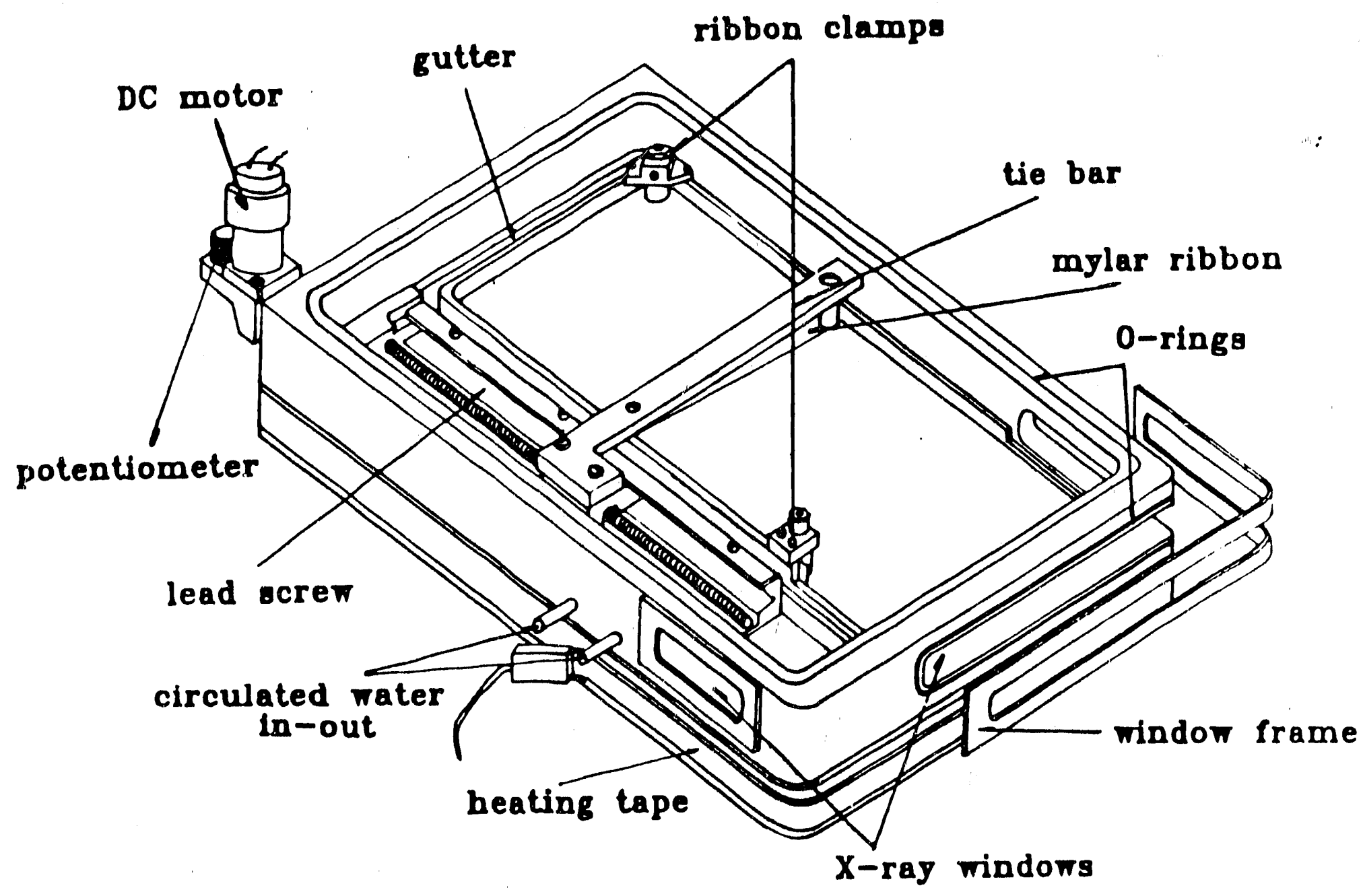

Fig. 1: View of $X$-ray trough with lid removed. 


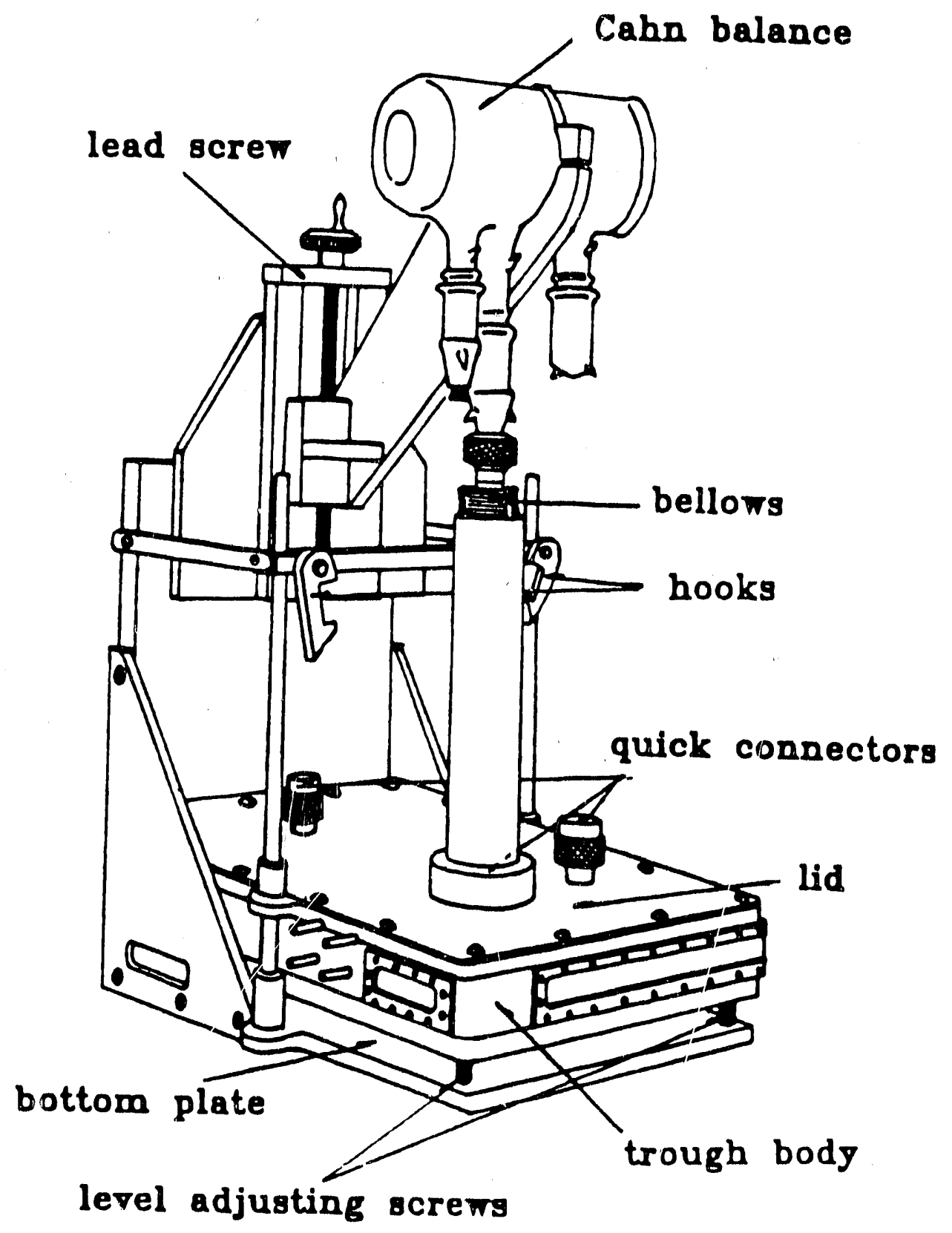

Fig. 2: Overall view of $X$-ray trough, showing lid, balance and mounting. 
(ii) Structure of the 'solid' phases in fatty acids and alcohols

We have observed second-order peaks ${ }^{7}$ (Fig. 3) from monolayers of heneicosanoic acid and heneicosanol in the highest-pressure ('solid') phase, and thus determined lattice structure for the first time in 'classical' monolayers ${ }^{8}$. The structure is distorted hexagonal (face-centered orthorhombic), as shown in the inset to Fig. 3 , , and is the same as that seen in the 'Rotator II' phase of paraffins.

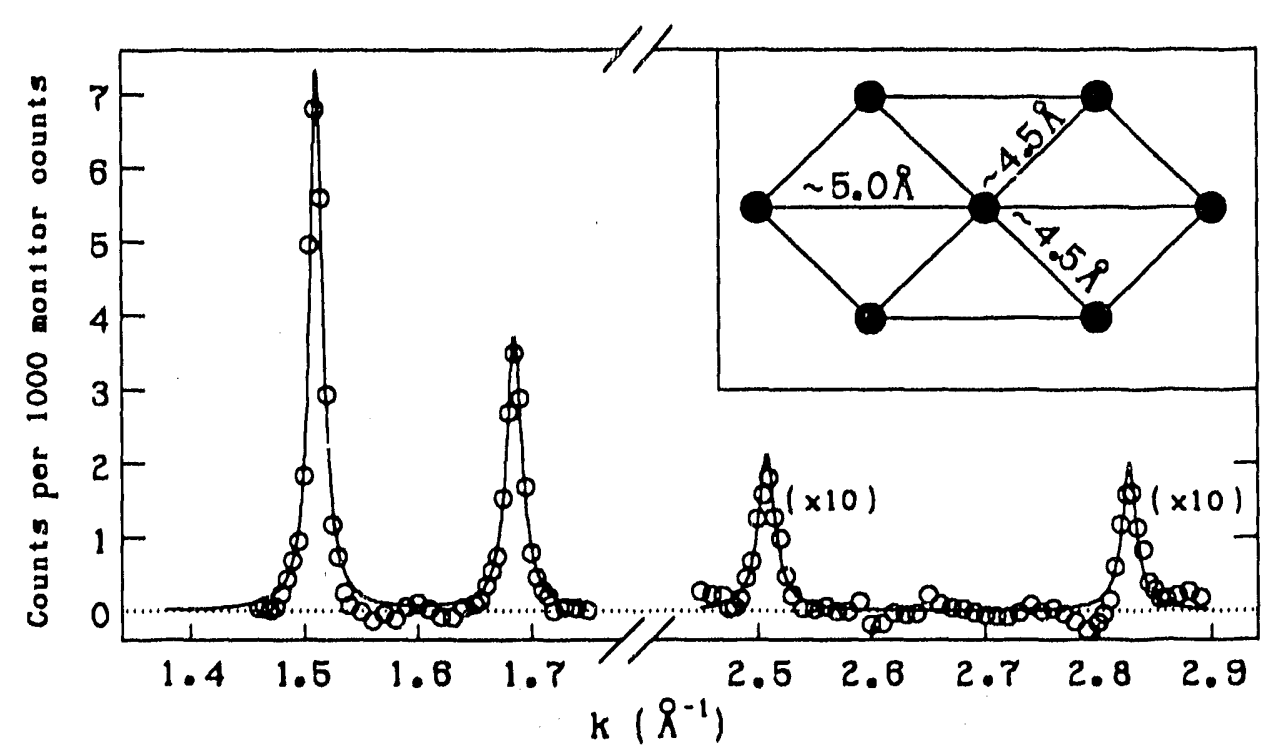

Fig. 3: X-ray diffraction data from a monolayer of heneicosanoic acld at $5.0^{\circ} \mathrm{C}$ and 35 dynes $/ \mathrm{cm}$ (background subtracted). The same peak positions are seen from heneicosanol at this temperature and pressure. INSET: lattice structure.

Ideally, the ratios of intensities of the peaks $1 \mathrm{~A}$ and $1 \mathrm{~B}$ should be $2: 1$, and the ratio 2A:2B should be 1:2 (from multiplicity, ignoring polarization effects and molecular structure factors). In fact the ratios are not only different from these values but are temperature-dependent. We have performed a model calculation assuming that the intensity variations arise from tilting of the molecules, and we find that the data can be explained with quite small tilt angles $\left(<7^{\circ}\right)$. Unexpectedly, the direction of tilt changes $90^{\circ}$, from one of the symmetry axes of the lattice to the other, at about $5^{\circ} \mathrm{C}$. This result, unexplained at the 
time, makes considerably more sense in connection with the phase diagram discussed in Part iv, below. For further details, see Ref. 7.

\section{(iii) Effect of subphase ions on monolayer structure}

Metallic ions are well known to alter the properties of fatty acid monolayers on the surface of water. The addition of minute quantities of these ions reduces the solubility of the monolayer material, improves the transfer ratio of monolayers to solid surfaces and, depending on $\mathrm{pH}$, can produce highly viscous films. Over the years, a large number of experiments has been performed to study the role of metallic ions in modifying the characteristics of these monolayers, but little is known about their structures.

Using $\mathrm{X}$-ray diffraction, we have studied heneicosanoic acid monolayers in the highest-pressure phase (the phase commonly used for Langmuir-Blodgett deposition), in the presence of $\mathrm{Cu}^{2+}$ and $\mathrm{Ca}^{2+}$ in the subphase. A full description of our experiments and results is contained in Ref. 9; the following is a selective summary.. All diffraction scans were taken at 25 dynes/cm., which is above the highest-pressure discontinuity seen in the isotherms. The $\mathrm{pH}$ region studied was 2-5.9 for $\mathrm{Cu}^{2+}$, and 2-11 for $\mathrm{Ca}^{2+}$; at higher $\mathrm{pH}$, hydroxide precipitation becomes visible. Our studies were conducted at $5^{\circ} \mathrm{C}$, where the signal to background in diffraction scans is 3-5 times better than that at room temperature.

Fig. 4, top left, shows the transition pressures seen in the isotherms as a function of $\mathrm{pH}$ in the presence of $\mathrm{Ca}^{2+}$. For $\mathrm{pH}<6.6$, there are two transitions; these isotherms are similar to those recorded from pure heneicosanoic acid monolayers at $\mathrm{pH}=2$. For $6.6<\mathrm{pH}<9.8$, only one transition remains; and for $\mathrm{pH}>9.8$, the transitions disappear completely. Therefore, three regions are denoted I-III as shown in the figure. The diffraction data exhibit two first order peaks when $\mathrm{pH}<10.8$; only one of the peaks remains at $\mathrm{pH}=10.8$ and 11. One can see that the diffraction data can be divided into the same three regions as for the isotherms: the peak positions are constant within each region but change at the boundaries between regions. It is known ${ }^{10}$ that the $\mathrm{pK}_{\mathrm{a}}$ is about $6-6.5$ for stearic 

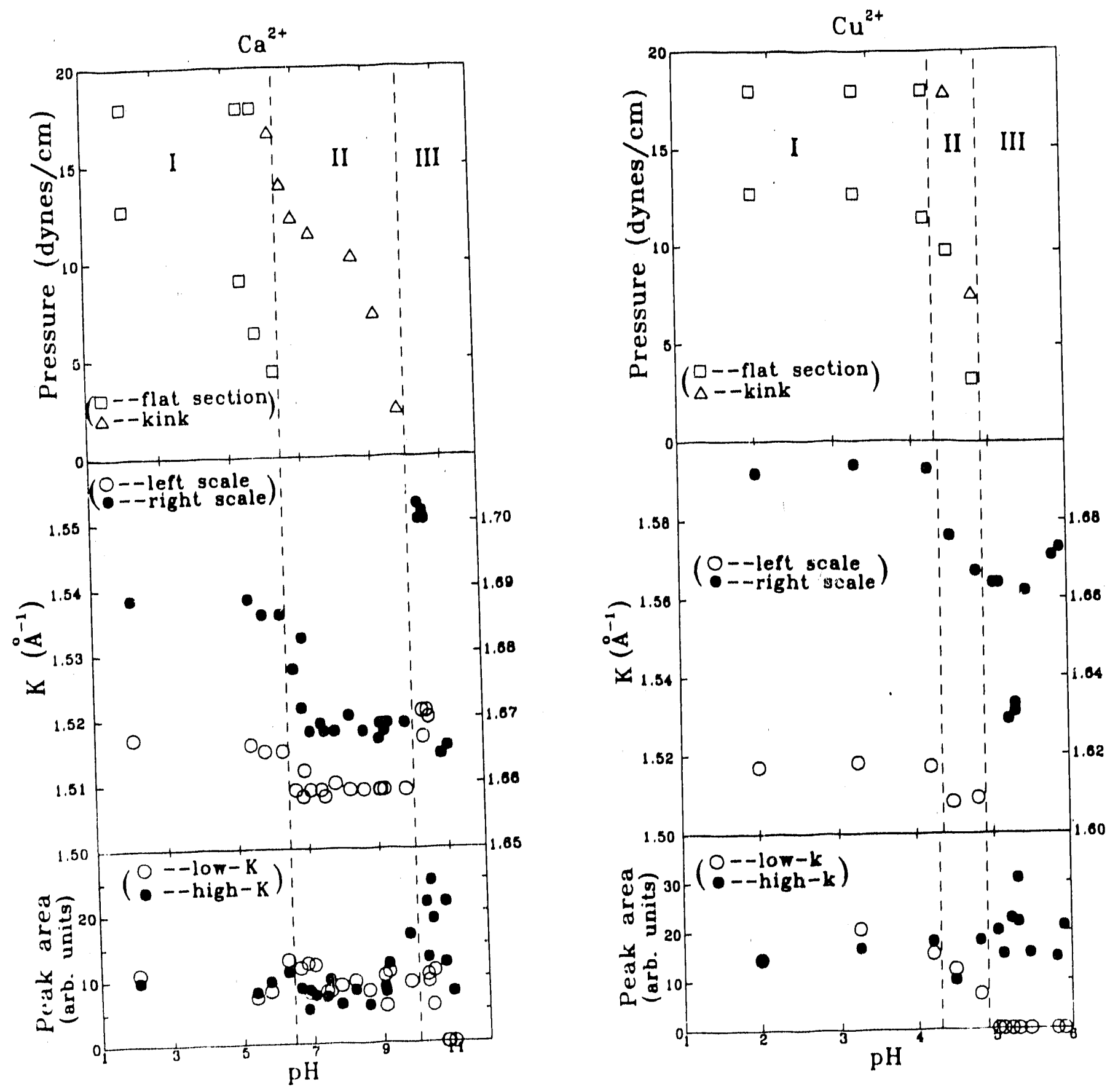

Fig. 4: Summary of isotherm and diffraction data from heneciscspoic acid monolayers with lons in the subphase. TOP: pressure(s) at which isotherms show dlscontinulties. MIDDLE: $X$-ray diffraction peak positions. BOTTOM: Diffraction peak intensities. The graphs at left are for $\mathrm{Ca} 2+$ and those at right are for $\mathrm{Cu} 2+$. The $\mathrm{pH}$ regions $\mathrm{I}-\mathrm{III}$ are identified by changes in the appearance of isotherms; the dotted lines Indicate the boundaries of these regions. 
acid monolayers with $\mathrm{Ca}^{2+}$; at $\mathrm{pH} \approx 9-10$, the mole fraction of calcium stearate is essentially zero. These values correspond approximately to the $\mathrm{pH}$ at the boundaries between regions (Fig. 4).

In the presence of $\mathrm{Cu}^{2+}$ as well, we can classify three $\mathrm{pH}$ regions according to isotherm features, as shown in Fig. 4, top right. Region $I$ is at $\mathrm{pH}<4.2$ with two transitions; region II is at $4.2<\mathrm{pH}<5.0$, also with two transitions but with the higher-pressure transition changed from a flat section to a kink; and region III is at $5.0<\mathrm{pH}<5.9$ where there is no visible transition. There are two first-order peaks in region I and II; only one of them is visible in region III. As with $\mathrm{Ca}^{2+}$, the boundaries of the isotherm regions also mark structural transitions. Although little data regarding chemical composition is available for this system (unlike $\mathrm{Ca}^{2+}$ ), the trends in the data are the same: we see a correspondence between the increasing adsorption of $\mathrm{Cu}^{2+}$ ions on the molecules and the structural variations in the monolayers.

In region III, however, the data behave differently in the two cases and show dramatic changes. With $\mathrm{Ca}^{2+}$ the higher-k peak, after having shifted upwards quite sharply at the boundary between regions II and III, drops back to close to its former position at the highest $\mathrm{pH}$ values. With $\mathrm{Cu}^{2+}$ the higher-k peak moves sharply down and then back to its previous position around $\mathrm{pH}=5.2$. Although these changes occur within very narrow $\mathrm{pH}$ regions, they are quite reproducible.

It is most likely that all 'two peak' structures are distorted hexagonal; the difference lies in the lattice dimensions. These differences appear to be induced by variations in the proportion of acid, divalent soap and basic soap molecules. The 'one-peak' structure with either ion appears to correspond to the formation of basic soap, and may be due to the formation of an undistorted hexagonal structure, or to a tilting of the chains in the direction of the $5.0 \AA$ bond in the distorted hexagonal lattice (see Fig. 3). One can even speculate that the shifts of the peak positions at lower $\mathrm{pH}$ values are also due to various tilts of the molecules. We do not as yet have a full explanation for the changes seen within Region III, 
although we expect that (since the shifts are $\mathrm{pH}$-driven) some yet-unidentified chemical reaction threshold may be associated with each change. To summarize, we have seen that the trends in the diffraction data are the same with the two ions (although the changes occur at different $\mathrm{pH}$ values) except very near the hydroxide precipitation region. We have identified several 'two-peak' diffraction patterns and a 'one-peak' pattern. Variation in lattice dimensions corresponds to variations in the form of the isotherm, and apparently to changes in the cherisical composition of the monolayers.

\section{(iv) Phase diagrams of acid and alcohol monolayers}

In 1988, we published a study ${ }^{5}$ of the phase transition at the 'kink' seen in the isotherm of heneicosanol monolayers. At room temperature, a single peak at $1.50 \AA^{-1}$ was seen at high pressures; as the pressure was lowered to below the kink, this peak gradually became smaller and disappeared. However, the peak did not widen, so that the phase transition being studied was not melting; we suggested at that time that perhaps increasing numbers of gauche defects were responsible for the loss of peak intensity. We also found that, as a function of temperature above the kink, the single diffraction peak at room temperature split into two peaks at lower temperatures, implying a hexagonal-to-distortedhexagonal similar to that seen in bulk paraffins (where it is called a Rotator I to Rotator II transition).

Ref. 5 was the first study of Langmuir film structure as a function of temperature as well as pressure; however, our most recent experiments have helped amplify the early work. (A full report is given in Ref. 11.) We studied heneicosanoic acid in the range 1$8^{\circ} \mathrm{C}$, where the isotherms show a variety of interesting features and trends (Fig. 5). For $\mathrm{T} \leq 2.5^{\circ} \mathrm{C}$, the isotherms show a long plateau plus a rounded change of slope at a higher pressure; for $3^{\circ} \mathrm{C} \leq \mathrm{T} \leq 5.5^{\circ} \mathrm{C}$, the single plateau appears to have split into two shorter ones; and for $\mathrm{T} \geq 6^{\circ} \mathrm{C}$, each isotherm contains a plateau and a "kink". For ease of reference, four regions in Fig. 5 are labelled A-D as shown. 


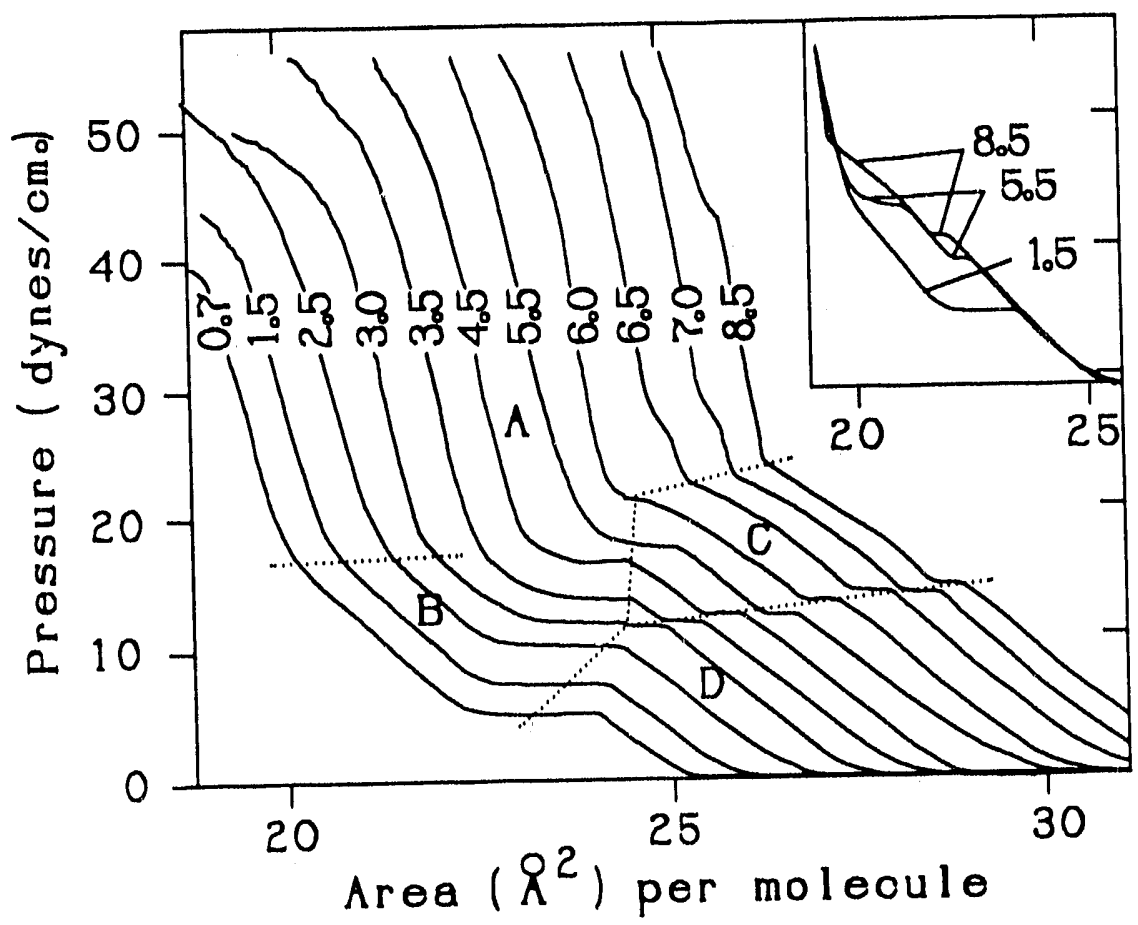

Fig. 5: Isotherms for Langmuir monolayers of heneicosanoic acid (labels on isotherms indicate temperature). The $x$-axis labels are correct for the first isotherm only; the cthers have been shifted horizontally for clarity. The dotted lines connect similar features; the letters A-D are used to label regions. In the inset, three isotherms are shown overlapped.

We performed in-plane ' $2 \theta^{\prime}$ ' scans as a function of pressure at $\mathrm{T}=1.0^{\circ} \mathrm{C}, 2.0^{\circ} \mathrm{C}$, $3.5^{\circ} \mathrm{C}, 5.0^{\circ} \mathrm{C}, 6.5^{\circ} \mathrm{C}$ and $8.0^{\circ} \mathrm{C}$. We found that when the isotherms are similar, the diffraction data are similar. All peaks seen were resolution limited, implying correlation lengths larger than $\sim 500 \AA$.

Within area A, two first-order in-plane peaks are seen at $1.50 \AA^{-1}$ ('Peak l') and $1.67 \AA^{-1}$ ('Peak II'), just as in Fig. 3. Although we did not look for second-order peaks during these experiments, there is little doubt that the structure in Region $\mathrm{A}$ is the same distorted hexagonal structure determined in Ref. 7, with essentially vertical chains (the tilt angle may not be exactly zero, but it is small).

Moving down to Region B, we find (see Fig. $6,1^{\circ} \mathrm{C}$ data) that Peak II remains in the plane as the pressure is lowered, while Peak I moves off it (i.e. $\mathrm{k}_{\mathrm{z}}$ becomes non-zero). The 
explanation for this behavior is straightforward: the chains tilt in the direction of the $5 \AA$ 'bond' (see schematic of the distorted hexagonal structure in Fig. 3). On the other hand, moving from Region $\mathrm{A}$ down to Region $\mathrm{B}$ (see $5^{\circ} \mathrm{C}$ and $8^{\circ} \mathrm{C}$ data in Fig. 6) we find that both peaks move off the plane, with Peak II being further off the plane than Peak I. Only one reasonable explanation is possible: tile chains in Phase $\mathrm{C}$ are tilted, as in Phase $\mathrm{B}$, but the tilt direction is now normal to the $5 \AA$ 'bond'. Thus the boundary between region $B$ and Region C (not well demarcated in our experiments) is a 'swivelling transition'. Note also that the A-C transition is first-order at $5^{\circ} \mathrm{C}$ but continuous at $8^{\circ} \mathrm{C}$; both isotherms and diffraction data are consistent as regards the order of the transitions.

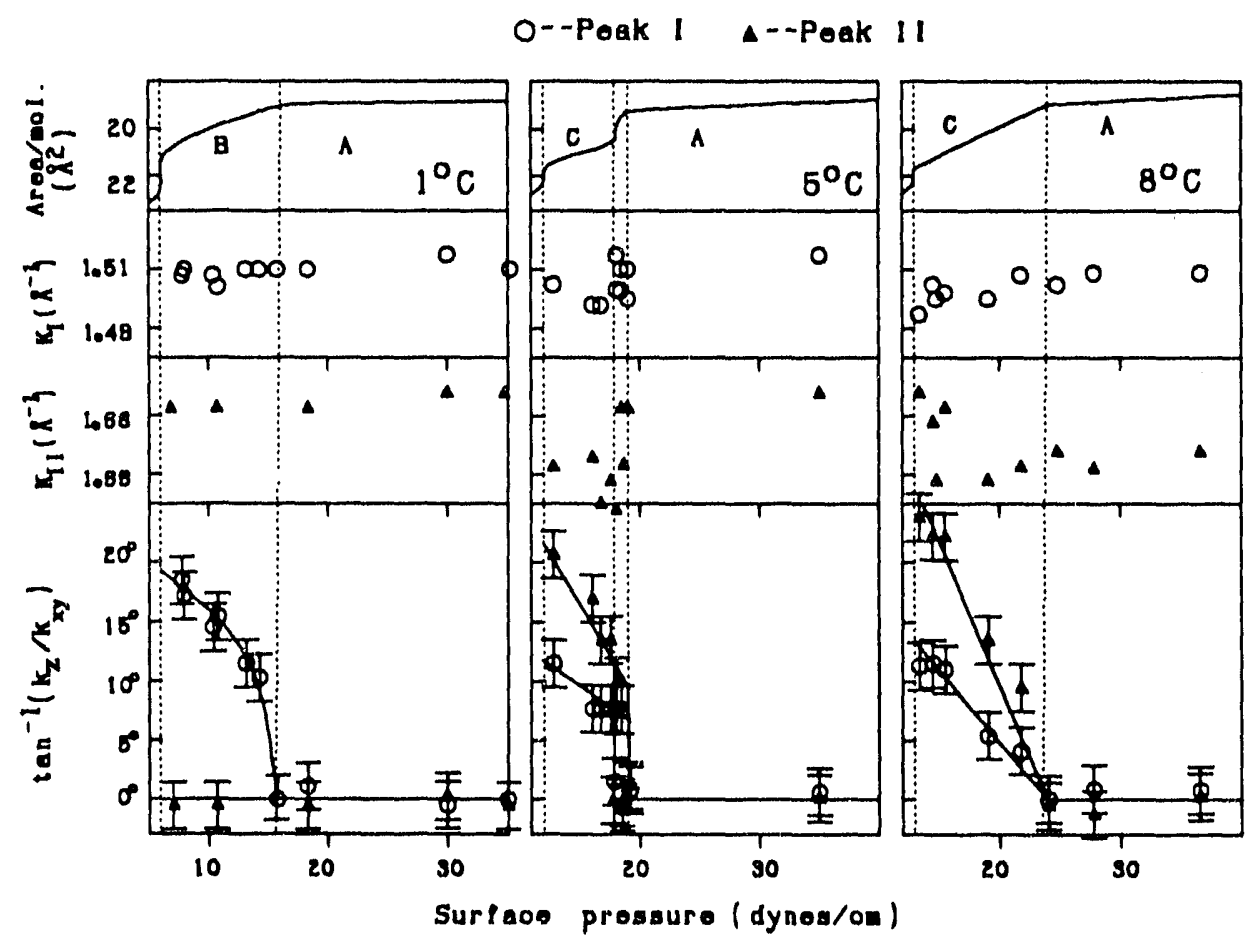

Fig. 6: Isotherm segments (top), diffraction vector magnitudes (center) and angles made by diffraction vectors to the horizontal (bottom), as a function of pressure at three representative temperatures. Only the regions $A, B$ and $C$ are shown.

In light of the above, the phase transition in Ref. 5 is most probably a tilting transition as well; since only in-plane scans were performed, movement of peaks away from the plane would be seen as a loss of peak intensity. Also, the change in tilt direction seen in 
Ref. 7 within Phase A (the actual tilt angles are very small) may be a 'memory effect': the tilt directions are the same as in the phase ( $B$ or $C$ ) seen at lower pressure at the same temperature!

In Region D we see a completely new phase, which we label 'expanded solid'. It shows a single in-plane diffraction peak, at $1.44 \mathrm{~A}^{-1}$ : in other words, at a position completely different from the peaks seen at higher pressures. This is an unexpected result: for generations, people working in the field have labelled the low-pressure phase 'liquid', but we see a resolution-limited diffraction peak.

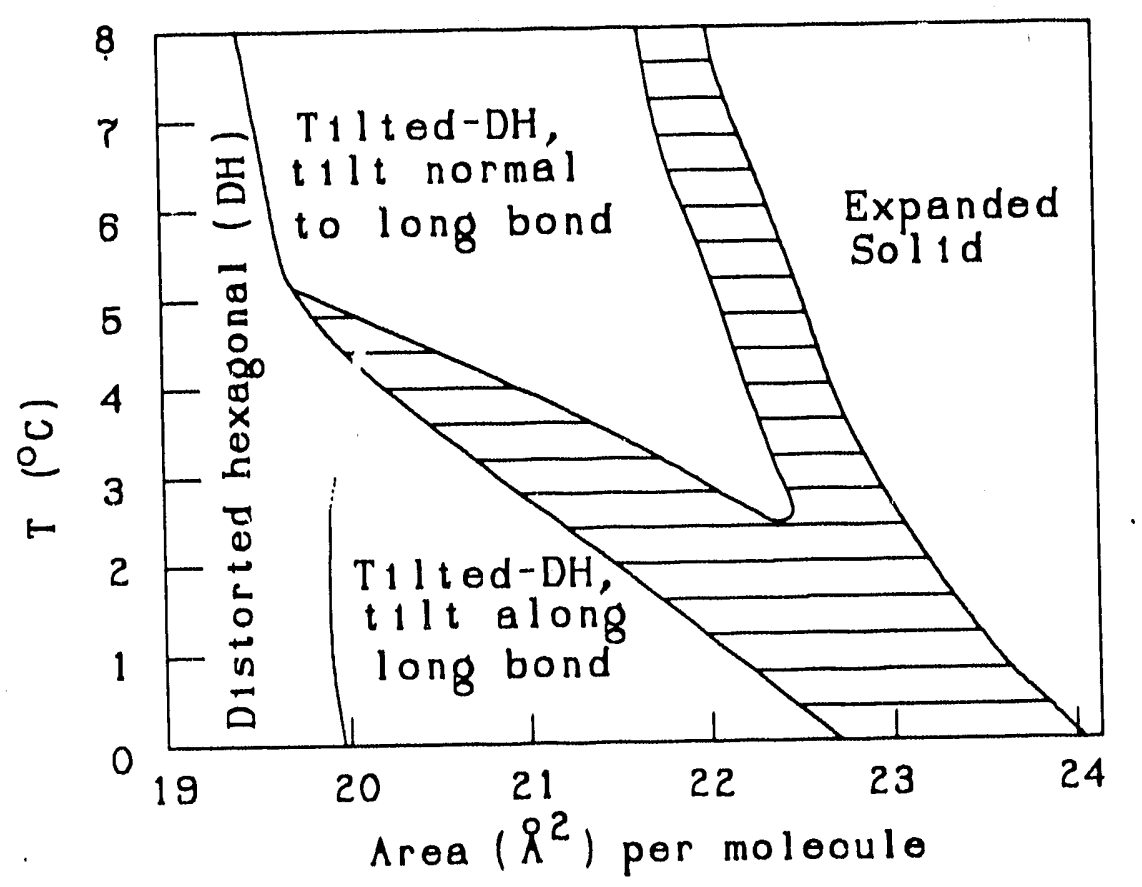

Fig. 7: Proposed phase dlagram (striped areas are coexlstence regions, dotted lines indicate uncertainty regarding the exact termination of the phase boundary).

All these conclusions are summarized in Fig. 7. We see two solid structures (distorted hexagonal and 'expanded solid'), and for the distorted hexagonal structure we identify tilted and untilted forms. We do not see 'liquid expanded' and 'liquid condensed' phases; while liquid phases will undoubtedly appear at higher temperatures, the common 
practice of looking at isotherms and labelling regions 'LE', 'LC', solid, etc. (in sequence from low to high pressure) stands discredited as a result of this work. In fact, monolayers have a richer variety of structures than previously realized; further exploration, as a function not only of temperature and pressure but of chain length, head group, $\mathrm{pH}$, etc., is likely to prove extremely rewarding.

\section{Flow of surfactant across a thin liquid film wetting a solid substrate}

Studies of wetting phenomena continue to be of both scientific and technological value. Although much attention has lately been focused on the critical properties associated with the wetting transition, the static and dynamic properties of adsorbed liquid films (with thicknesses larger than molecular dimensions) are of equal interest. ${ }^{12}$ Although resistivity ${ }^{13}$ (for conducting films) and ellipsometry ${ }^{14}$ (for transparent films) have provided valuable information, the number of techniques available to probe such films is unfortunately rather limited; thus the development of a new probe (as described here) should be of particular value.

We have developed a technique which makes use of an organic monolayer on the surface of water. In an earlier paper, ${ }^{15}$ we described a curious phenomenon: when a flintglass microscope slide was lowered until it touched the surface of water $n$ which a monolayer of the surfactant valinomycin had been spread, the monolayer slowly transferred to the glass surface. At higher surface pressures, the amount of material transferred to the slide (calculated from the change in the area at constant pressure of the Langmuir film on the trough) implied that the film had climbed a distance of order $10 \mathrm{~cm}$. It was thus natural to ask whether the glass strip might function as a "bridge" if the other end were in contact with a second Langmuir trough; i.e., whether we could continuously transfer surfactant molecules from one trough to another over the thin film of water wetting the glass slide by maintaining a differential surface pressure, $\Delta \Pi$. This surface pressure difference would 
maintain a surface tension gradient and, via the Marangoni effect, drive the motion of the liquid.

Carrying out the proposed experiment required the construction of a "double" Langmuir trough. ${ }^{16}$ The new instrument sits in a stainless steel enclosure; the double walls of the enclosure allow a thermostating fluid to be circulated, and (when the lid is closed) the system is hermetically sealed. Both features are vital if we are to be certain that the water in the two troughs, the glass bridge, and the surrounding atmosphere are in thermodynamic equilibrium (involving both a constant temperature and a saturated vapor pressure). Although the instrument may be equipped with two separate troughs, we used a single long trough; a fixed mylar barrier at its center divided the water surface into two halves, and moving barriers on each side allowed the two monolayers to be independently maintained at the desired surface pressures.

Fig. 8 shows the average velocity $V_{S}$ across a $U$-type bridge as a function of the differential surface pressure (the curve through the points will be discussed shortly). Note that the transfer is completely reversible (i.e. changing the sign of $\Delta \Pi$ causes the material to flow in the opposite direction) and that the flow velocity is approximately linear in the applied surface pressure differential.

We have also developed a theory for the thickness of an entrained liquid film induced by surfactant flow. It is a generalization of an earlier theory of Landau and Levich to include the van der Waals interaction of the film with the substrate. It is found that for a range velocities, the thickness is governed by the van der Waals dispersion force and is independent of surfactant velocity; as the velocity is increased above this range the film becomes thicker and the thickness depends on velocity as $V_{s}^{2 / 3}$; this is the Landau-Levich limit and in this limit the van der Waals dispersion force becomes irrelevant. Our theory provides a new method to determine the retarded Hamaker constant associated with the liquid-solid interaction. 


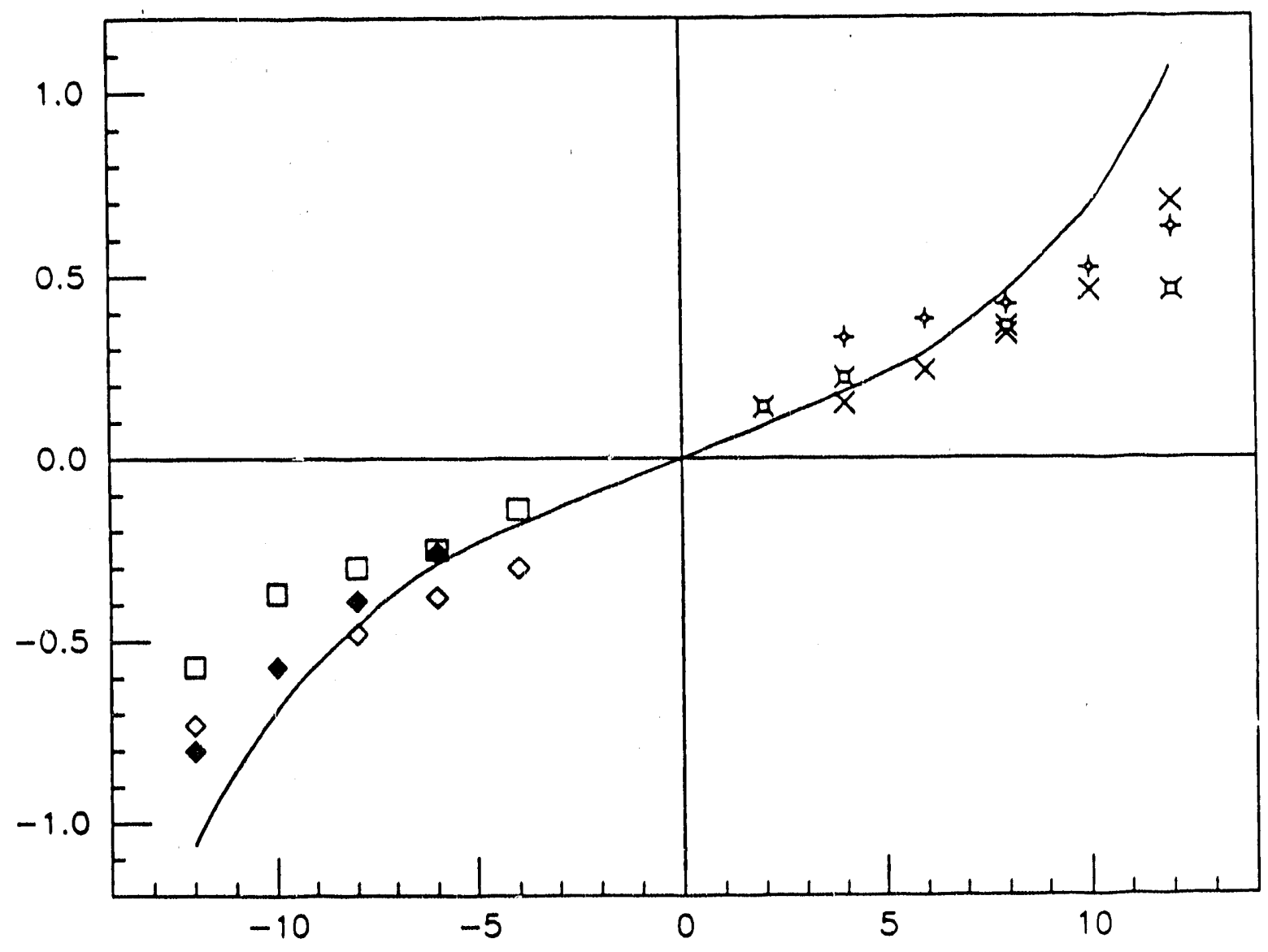

Fig. 8: Surfactant flow velocity as a function of driving pressure. The different symbols mark different runs involving both directions of surfactant transport. 
The theory involves an integration of the Navier-Stokes equation in the lubrication approximation. Although an analytic expression is available in the thin and thick film limits, detailed numerical integrations as a function of $V_{S}$ are required for intermediate values. The results of the calculations can be well represented by a power-law interpolation of the form:

$$
\mathrm{V}_{\mathrm{S}}=\left\{\left[(\gamma / \mu)\left(\ell_{\mathrm{VW}} / \ell_{\mathrm{C}}\right)^{5 / 4}\left(\Delta \Pi \ell_{\mathrm{C}} / \gamma \mathrm{L}\right)\right]^{\mathrm{n}}+\left[(1.2 \gamma / \mu)\left(\Delta \Pi \ell_{\mathrm{c}} / \gamma \mathrm{L}\right)^{3}\right]^{\mathrm{n}}\right\}^{1 / \mathrm{n}}
$$

which accurately interpolates between the limiting $V_{S} \propto \Delta \Pi$ (van der Waals dominated thin film) and $V_{S} \propto(\Delta \Pi)^{3}$ (classical thick film) regimes. A value of $n=2$ represents the numerical calculations with a maximum error of $10 \%$ (which is presently better than the experimental error). Here $\ell_{\mathrm{C}}=(2 \gamma / \rho \mathrm{g})^{1 / 2}$ is the capillary length, and $\ell_{\mathrm{VW}}=(\mathrm{B} / \rho \mathrm{g})^{1 / 5}$ is a van der Waals length.

The smooth curve in Fig. 1 is a fit of the data to the full numerical version of the theory. The value of the retarded Hamaker constant which best fits the data is $B=2.6 \mathrm{x}$ $10^{-15} \mathrm{~cm}^{3} \mathrm{~g} / \mathrm{s}^{2}$. Although water is not, strictly speaking, a van der Waals liquid, the value is nonetheless reasonable. The thickness of the film in the low velocity limit, obtained using the formula in Ref. 17 is $h_{0}=\ell_{c}\left(\ell_{\mathrm{Vw}} / \ell_{\mathrm{C}}\right)^{5 / 4}=0.5 \mu \mathrm{m}$.

For a more complete description of this work, see Refs. 17 and 18.

\section{E. Mechanical properties of surface monolayers}

We have devised a simple method for detecting the onset of a shear modulus in Langmuir films. We measure monolayer pressure using a filter paper Wilhelmy plate oriented in the direction of compression (using a traditional uniaxial-compression monolayer trough). We then repeat the experiment with the plate turned $90^{\circ}$. If the monolayer is fluid, the orientation of the plate will make no difference. However, if the monolayer is solid and thus exhibits a static shear modulus, the stresses will be different along and normal to the compression direction, and the difference between the two isotherms can be 
used as a measure of the shear modulus (this has been made quantitative in Ref. 20). The advantage of this method is that it can be used by anyone with a Wilhelmy-plate Langmuir trough: no special shear apparatus is necessary. If a two-arm halance is used for force measurement, the difference may be measured directly (and thus more accurately) by suspending orthogonal plates from the two arms.

We have used this method to study three fatty acids: $\mathrm{C}_{n-1} \mathrm{H}_{2 n-1} \mathrm{COOH}$ with $n=15$, 18 and 24. Isotherms at room temperature are shown in Fig. 9; differences between isotherms determined with parallel and perpendicular plates are shown (with considerably expanded scales) in Fig. 10. When $n=15$, there is no observable shear modulus up to 30 dynes/cm., even though there is a clearly visible transition in the isotherm. When $n=18$, the film is solid-like (with a small but observable shear modulus) at all pressures; the transition in the isotherm does not show in the mechanical properties. When $n=24$, the film appears to be solid everywhere, but the transition has a clear signature in the mechanical properties: the film becomes much stiffer as the pressure is increased through the transition in the isotherm.

This work has been described in detail in Ref. 20, which predates our recent X-ray work (Ref. 7) by over a year. Nonetheless, it is tempting to attempt a reinterpretation of this data with the benefit of hindsight. Qualitatively, increasing chain length should be the same as decreasing temperature, and vice versa. Thus phase transitions that are at negative pressure (and thus unobservable) at a given chain length might appear when the length is decreased, while transitions that are at pressures too high to be observed (the surface tension of water sets a fundamental limit at 70 dynes $/ \mathrm{cm}$, and the practical limit is even lower) might appear when the chain length is increased. Presumably, therefore, the transitions observed in $\mathrm{C}_{15}$ and $\mathrm{C}_{21}$ are quite different, even though the isotherms look similar. The $C_{15}$ phases could both be liquid; as suggested earlier, the fact that our $\mathrm{X}$-ray experiments observe solid phases only does not mean liquid phases will not appear at higher temperature or shorter chain length. The phase transition in $\mathrm{C}_{18}$ could be a tilting transi 

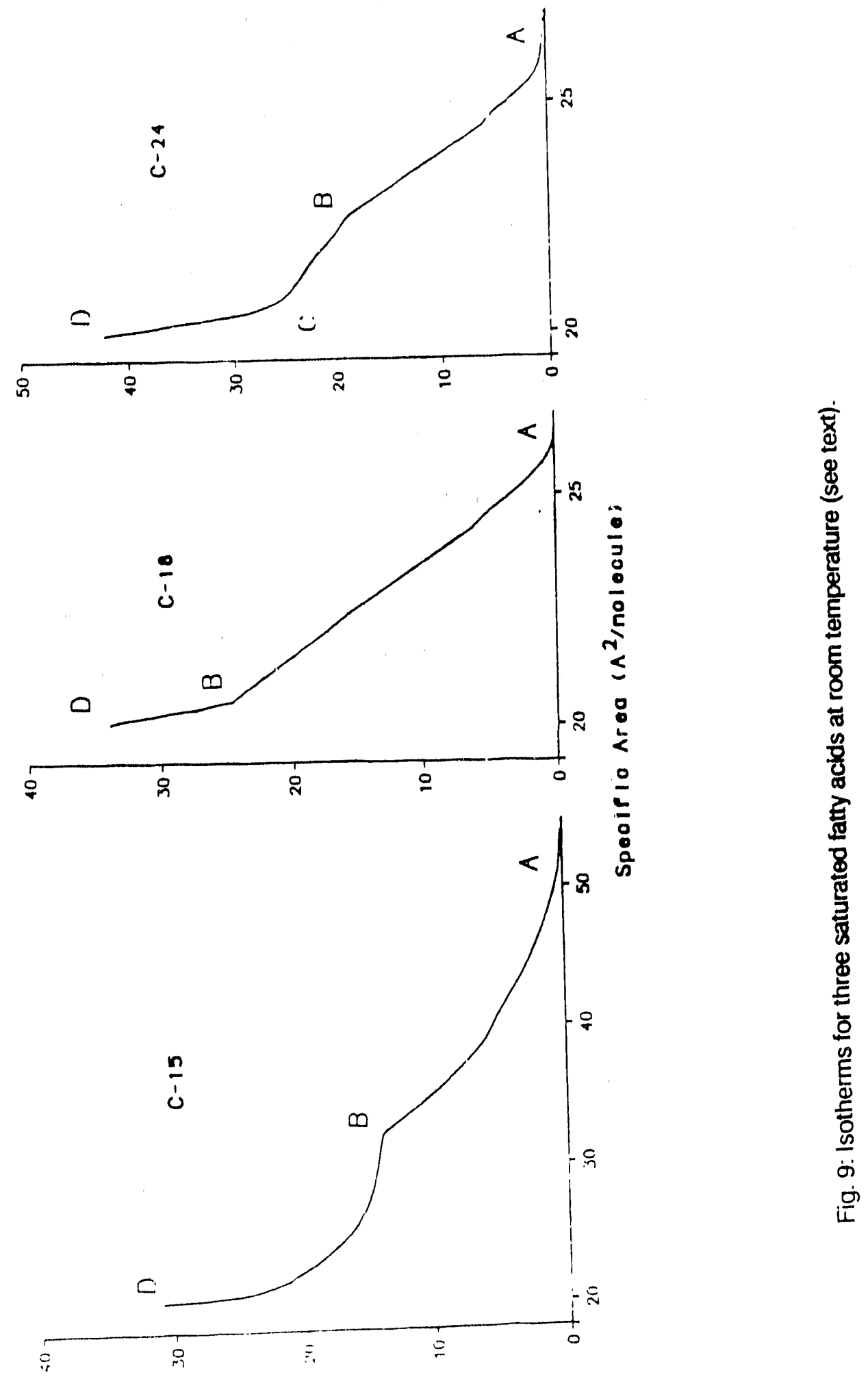

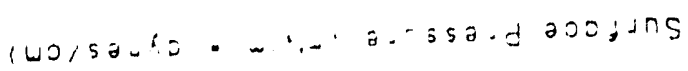




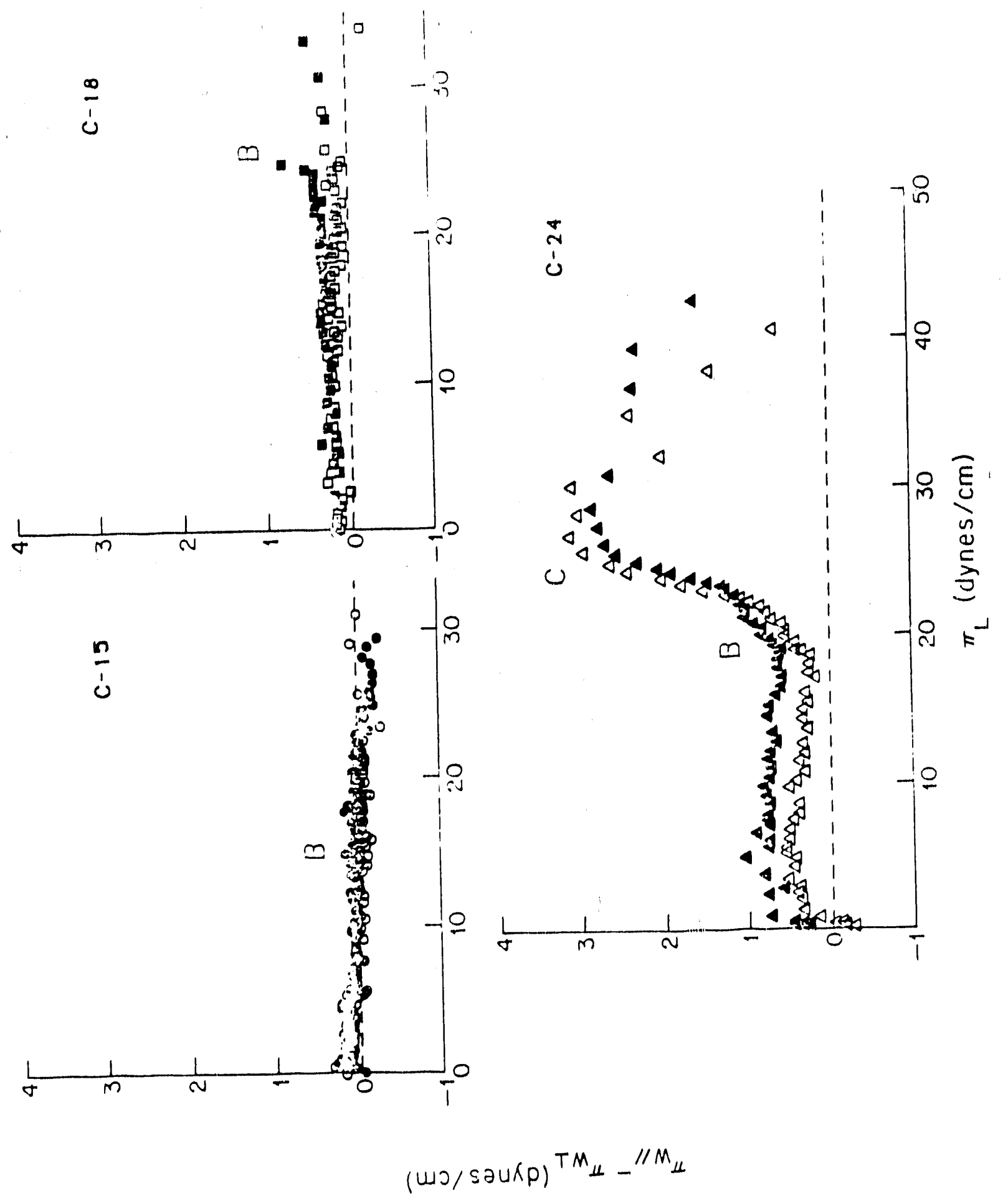

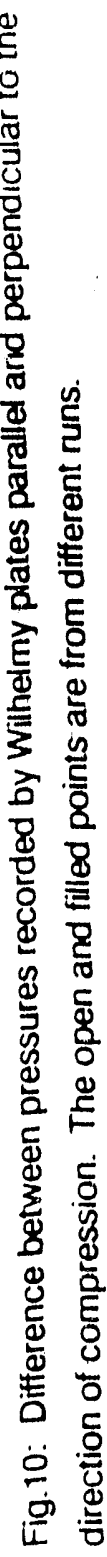


tion, a solid-solid trarsition which probably has no effect (or only a weak effect) on the shear properties. In $\mathrm{C}_{24}$, perhaps, these transitions are driven out of the observed pressure range and a true structural transition appears: one showing a first-order step in the isotherm as well as a distinct change in shear properties. The B-D and C-D transitions in $\mathrm{C}_{21}$ (see X-ray data) would be examples of such transitions.

\section{F. Static and dynamic contact angles as a probe of Langmuir-Blodgett deposition}

It has long been known that depending on the subphase conditions, multilayer filmıs that are being built up by the Langmuir Blodgett technique may change over from an initial $\mathrm{Y}$ type mode (where a monolayer is deposited on entering and leaving the subphase) to $\mathrm{X}$ type (where it deposits only on the entering) as the dip number increases. Much has been written about the microscopic processes leading to this behavior; we will not attempt to review this literature here. Perhaps the only way to settle the question is to use synchrotron radiation to examine film structure in situ as an LB film is built up (we propose to do this during the next grant period). meanwhile, to try and gather more information on this phenomenon, we have carried out a systematic study of the relaxation of the contact angle when LB deposition is suddenly stopped at various stages in the film evolution. This work is an outgrowth of the work described in our last Progress Report, which highlighted the importance of the contact angle as an in situ (although, unlike X-rays, macroscopic) probe of the process of deposition.

For cadmium stearate, deposition can proceed in two ways: i) always in the Y-type (two way) mode, or ii) with a gradual changeover from $Y$-type to $X$ type mode. The dynamic and static advancing contact angle and its relaxation behavior are independent of the deposition mode. The behavior of the receding contact angle, however, has two features: the static values to which the receding contact angles relax depend on the concentration of $\mathrm{Cd}^{+}+$ions in the subphase, and the relaxation times themselves depend strongly on 


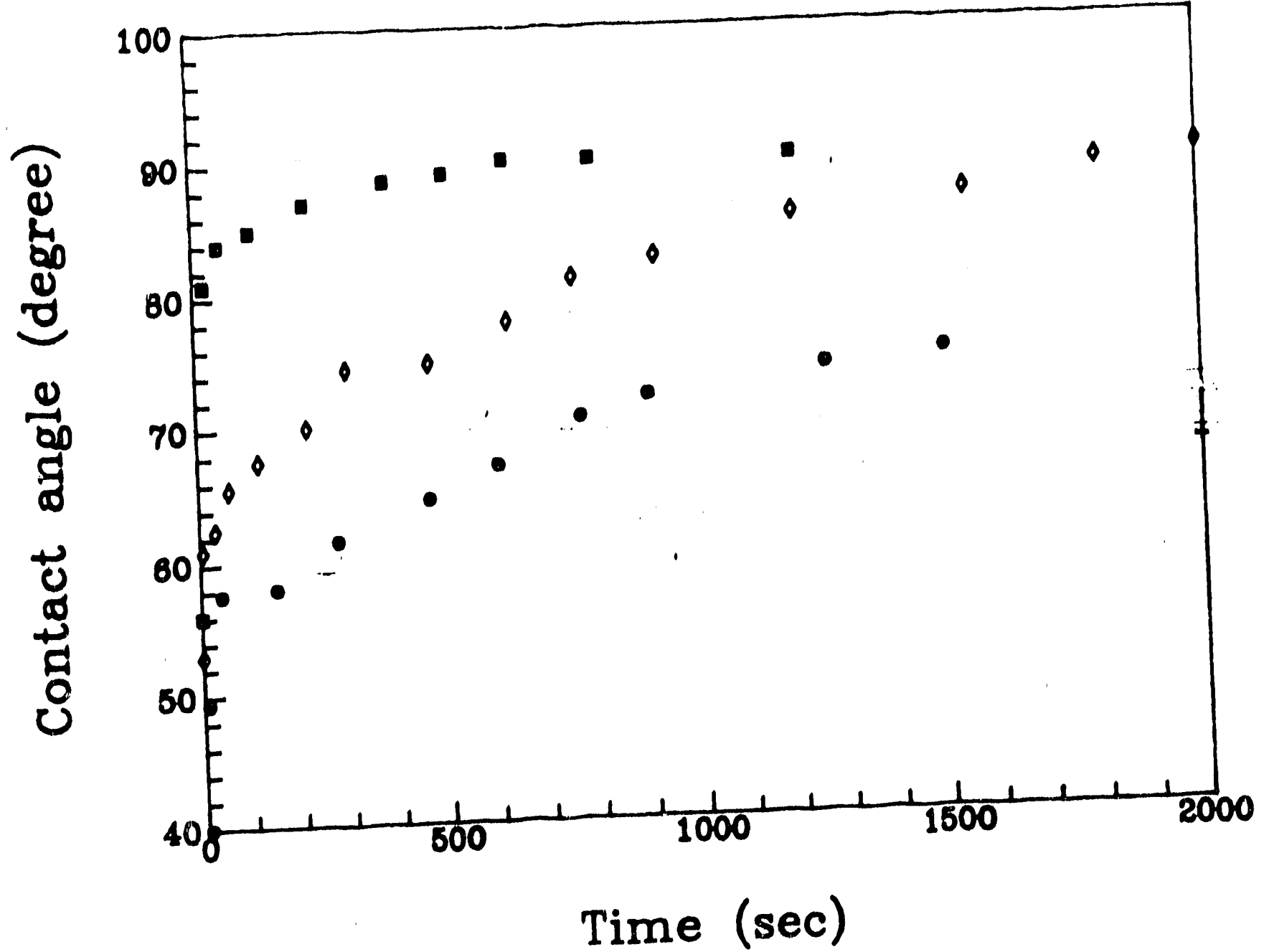

Fig. Relaxation behavior of receding contact angles during Langmulr-Blodgett deposition of cadmlint stearate:

- Y typ depostion (subphase: $4 \times 10^{-2} \mathrm{M} \mathrm{CdC1}_{2}$, unbuffered, 5 th upstroke); note that the relaxation is not completed by the end of the trace (l.e. $>2000$ sec.)

$\checkmark Y$ type deposition (subphase: $2.5 \times 10^{-3} \mathrm{M} \mathrm{CaCl}_{2}$, unbuffered 5 th upstroke, before the transition from $Y$ io $\mathrm{S}_{\mathrm{f}}$ rype deposition); note that the relaxatlon is essentlally complete by $1000 \mathrm{sec}$.).

- X type deposition (subphase: $2.5 \times 10^{3} \mathrm{MCdC}_{2}$, unbuffered, 14th upstroke, after the transition from $Y$ to $X$ type deposition); note that the relaxation is much faster and is essentlally complete by 400 soc. 
the deposition type, as shown in Fig. 11. The receding contact angles for $Y$ type films deposited from a subphase of $4.0 \times 10^{-2} \mathrm{M} \mathrm{Cd}^{++}$relax from an initial angle of $40^{\circ}$ to a static value of about $75^{\circ}$. Films deposited from a subphase of $2.5 \times 10^{-3} \mathrm{M} \mathrm{Cd}^{++}$, i.e. a somewhat more dilute solution, will undergo a transition from the $\mathrm{Y}$ to the $\mathrm{X}$ type mode. Prior to this transition the receding contact angles relax from approximately $50^{\circ}$ to $90^{\circ}$; however, the relaxation time is the same as at the higher concentration, about 450 seconds. After the transition from $\mathrm{Y}$ to $\mathrm{X}$ (at the lower concentration) the receding contact angles relax from $55^{\circ}$ to a static angle of $90^{\circ}$; however, the relaxation is more than 20 times faster than the Y mode.

Valinomycin predominantly deposits in a $\mathrm{Z}$ type mode. The dynamic/static advancing contact angles are $95^{\circ} / 75^{\circ}$, i.e., they change from hydrophobic $\left(>90^{\circ}\right)$ to hydrophilic $\left(<90^{\circ}\right)$. The dynamic/static receding contact angles are $30^{\circ} / 60^{\circ}$; i.e., they remain hydrophilic.

Further details of these experiments can be found in Ref. 19.

\section{G. References}

1. I. Langmuir, J. Am. Chem. Soc. 218, 1848 (1917)

2. see.g. G.L. Gaines, Jr., "Insoluble monolayers at liquid-gas interfaces" (Interscience, New York, 1966)

3. P. Dutta, J.B. Peng, B. Lin, J.B. Ketterson, M. Prakash, P. Georgopoulos and S. Ehrlich, Phys. Rev. Lett. 58, 2228 (1987)

4. K. Kjaer, J. Als-Nielsen, C.A. Helm, L.A. Laxhuber and H. Mohwald, Phys. Rev. Lett. 58, 2224 (1987)

5. S. W. Barton, B. N. Thomas, Stuart A. Rice, B. Lin, J. B. Peng, J. B. Ketterson and P. Dutta, J. Chem. Phys. 89, 2257 (1988)

6. B. Lin, P. Dutta and J.B. Ketterson, in preparation 
7. T. Bohanon, B. Lin, M. Shih, G. Ice and P. Dutta, Phys. Rev. B (Rapid Comm.), to be published

8. A second-order peak has previously been reported using an unusual molecule designed to cross-link in the piane: S.G. Wolf, L. Leiserowitz, M. Lahav, M. Deutsch, K. Kjaer and J. Als-Nielsen, Nature 328, 63 (1987)

9. B. Lin, T. Bohanon, M. Shih and P. Dutta, submitted to Langmuir

10. T. Sasaki and M.Muramatsu, Bull.Jpn. Chem. Soc. 24, 274 (1951); J. Bagg, M.B. Abramson, M. Fichamn, M.D. Haber and H.P. Gregor, J. Am. Chem. Soc. 86, 2759 (1964); D.W. Deamer, D.W. Meek and D.W. Cornwell, Lipid Research 8, 255 (1967); A. Matsubara, R. Matuura and H. Kimizuka. Bull. Jpn. Chem. Soc. 38, 369 (1965).

11. B. Lin, T. Bohanon, M. Shih and P. Dutta, submitted to Phys. Rev. Lett.

12. P.G. deGennes, Revs. Mod. Phys. 57, 827 (1985)

13. H. Ghiradella, W. Radigan and H.F. Frisch, J. Coll. Interf. Sci. 51, 522 (1975)

14. O.D. Kwon, Phys. Rev. Lett. 48, 185 (1982)

15. J.B. Peng, P. Dutta and J.B. Ketterson, Thin Solid Films 159, 215 (1988)

16. T. Armen, K. Halperin, P. Dutta and J.B. Ketterson, Revs. Sci. Instrum. 58, 822 (1987)

17. S.X. He and J.B. Ketterson, Phys. Rev. B. (Rapid Comm.) 40, 7417 (1989)

18. J.B. Peng, S.X. He, P. Dutta and J.B. Ketterson, Phys. Rev. B. (Rapid Comm.) 40, $7421(1989)$

19. J.B. Peng, S.X. He, P. Dutta, and J.B. Ketterson, submitted to Langmuir

20. "A study of the mechanical behavior of surface monolayers using orthogonal Wilhelmy plates", K. Halperin, P. Dutta and J.B. Ketterson, Langmuir 5, 161 (1989) 


\section{APPENDIX I: PAPERS SUPPORTED BY THIS GRANT (1/87-present)}

"X-ray diffraction study of an organic monolayer on the surface of water", P. Dutta, J.B. Peng, B. Lin, M. Prakash, J.B. Ketterson, P. Georgopoulos and S. Ehrlich, Phys. Rev. Lett., 58, 2228 (1987)

"Synchrotron diffraction studies of lead octadecanoate, tetracosanoic acid and 1eicosanol monolayers on water", B. Lin, J.B. Peng, J.B. Ketterson and P. Dutta, Thin Solid Films 159, 111 (1988)

"Using the transfer of a Langmuir monclayer as a probe of wetting", J.B. Peng, P. Dutta and J.B. Ketterson, Thin Solid Films 159, 215 (1988)

"Diffraction studies of Langmuir films", J.B. Peng, B. Lin, J.B. Ketterson and P. Dutta, in The Structure of Surfaces II (Springer Series in Surface Sciences Vol. 11), edited by J.F. van der Veen and M.A. van Hove (Springer-Verlag, 1988) pg. 564

"X-ray diffraction study of a Langmuir monolayer of $\mathrm{C}_{21} \mathrm{H}_{43} \mathrm{OH}$ ", S. W. Barton, B. N. Thomas, Stuart A. Rice, B. Lin, J. B. Peng, J. B. Ketterson and P. Dutta, J. Chem. Phys. 89, 2257 (1988)

"The structure of lipid monolayers on water", P. Dutta, in Chemical Applications of Synchrotron Radiation (Argonne National Laboratory Workshop Report ANL/APS-TM-4, 1989) p. 21

"A study of the mechanical behavior of surface monolayers using orthogonal Wilhelmy plates", K. Halperin, P. Dutta and J.B. Ketterson, Langmuir 5, 161 (1989)

"Kinetics of a structural phase transition in Langmuir films studied using X-ray diffraction", B. Lin, J.B. Peng, J.B. Ketterson, P. Dutta, B.N. Thomas, J. Buontempo and Stuart A. Rice, J. Chem. Phys. 90, 2393 (1989)

"Thickness of a liquid film on a solid substrate induced by steady-state surfactant flow", S.X. He and J.B. Ketterson, Phys. Rev. A (Rapid Comm.) 40, 7417 (1989) 
"Flow of a surfactant across a thin liquid film wetting a solid substrate", J.B. Peng, S.X. He, P. Dutta and J.B. Ketterson, Phys. Rev. A (Rapid Comm.) 40, 7421 (1989)

"Determination of the in-plane structure and molecular tilt of lipid monolayers on water using X-ray diffraction", T. Bohanon, B. Lin, M. Shih, G. Ice and P. Dutta, Phys. Rev. B (Rapid Comm.), to be published in March 1990 issue

"X-ray diffraction studies of the effects of calcium and copper ions on Langmuir monolayers of heneicosanoic acid", B. Lin, T. Bohanon, M. Shih and P. Dutta, submitted to Langmuir

"Measurement of contact angle relaxation during the deposition of LangmuirBlodgett films of cadmium stearate and valinomycin", J.B. Peng, S.X. He, P. Dutta, and J.B. Ketterson, submitted to Langmuir

"The phase diagram of a lipid monolayer on the surface of water", B. Lin, T. Bohanon, M. Shih and P. Dutta, submitted to Phys. Rev. Lett.

"A Langmuir trough for X-ray diffraction studies of lipid monolayers on the surface of water", B. Lin, P. Dutta and J.B. Ketterson, in preparation 


\section{APPENDIX II: TALKS'AND POSTERS COVERING WORK SUPPORTED BY THIS GRANT (1/87-present)}

Seminar, Iowa State University, 3/87 (Dutta)

Talk, APS March Meeting, New York, NY, 3/87 (Lin)

Talk, APS March Meeting, New York, NY, $3 / 87$ (Peng)

Seminar, Polytechnic Institute of New York, New York, NY, 4/87 (Dutta)

Seminar, University of Rhode Island, Kingston, RI, 4/87 (Dutta)

Talk, Second International Conference on the Structure of Surfaces, Amsterdam, Netherlands, 6/87 (Dutta)

Poster, Third International Conference on Langmuir-Blodgett Films, Goettingen, W. Germany, $7 / 87$ (Peng)

Seminar, Illinois Institute of Technology, Chicago, IL, 10/87 (Dutta)

Seminar, University of Chicago, Chicago, IL, 11/87 (Dutta)

Talk, APS March Meeting, New Orleans, LA, $3 / 88$ (Lin)

Invited talk, Argonne Workshop on Applications of Synchrotron Radiation, Argonne, IL, 9/88 (Dutta)

Invited talk, Midwest Solid State Conference, Lafayette, IN, 10/88 (Dutta)

Seminar, Carnegie-Mellon University, Pittsburgh, PA, 10/88 (Dutta)

Seminar, University of Wisconsin, Madison, WI, 11/88 (Dutta)

Invited talk, APS March meeting, St. Louis, MO, 3/89 (Dutta)

Invited talk, Fourth International Conference on Langmuir-Blodgett Films, Tsukuba, Japan, 4/89 (Dutta)

Invited talk, ACS meeting, Cleveland, $\mathrm{OH}, 5 / 89$ (Dutta)

Invited talk, Gordon Conference on The Chemistry of Supramolecules \& Assemblies, Plymouth, NH, 7/89 (Dutta)

Invited talk, Pittsburgh Diffraction Conference, 10/89 (Dutta)

Poster, Gordon Conference on Organic Thin Films, Oxnard, CA, 2/90 (Lin)

Invited lectures, NATO Summer Institute on Phase Transitions in Surface Films, Erice, Italy, 6/90 (Dutta) 

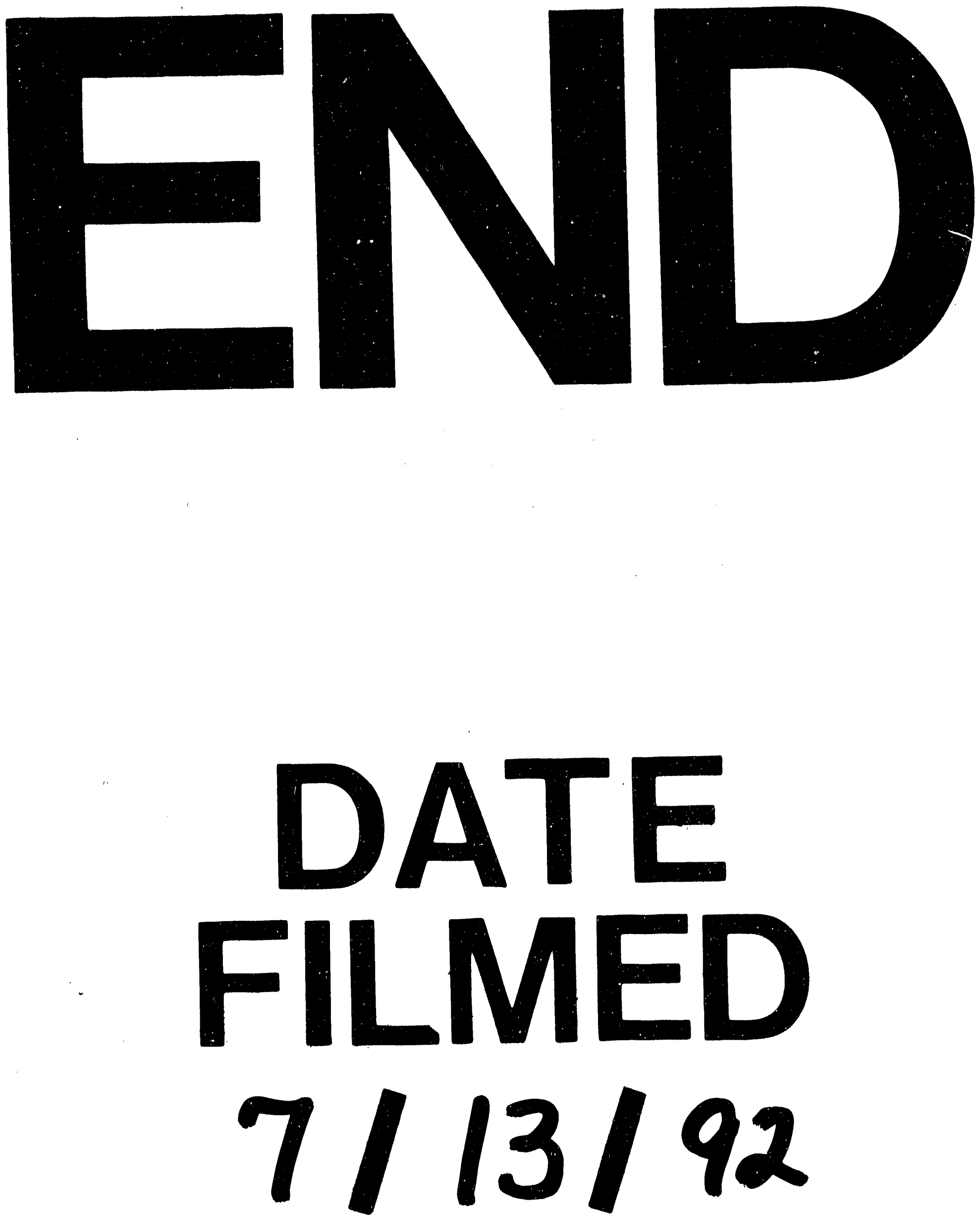

I 
